\title{
SHOULD VACCINATION BE A PRIORITY APPROACH FOR JAPANESE ENCEPHALITIS PREVENTION IN NEPAL?
}

\author{
Joshi A B*, Banjara M R*, Wierzba T* \\ * Institute of Medicine, Maharajgunj, Kathmandu, Nepal.
}

In Nepal, a total number of 27584 Japanese encephalitis (JE) cases and 5382 deaths have been reported, with an average case fatality rate of $19.5 \%$ in aggregate since 1978 to 2004. Past trend of the disease has shown that JE outbreaks are circumscribed and do not cover large areas. However, it depends on the flight range of the vector mosquitoes, presence of pigs as an amplifying hosts and the presence of a susceptible human population. During twenty six years period of time, the highest number of cases were reported in 1997 (2953 cases) and the second highest were in 1999 (2924 cases). Similarly, highest number of cases was reported from Far-western and Mid-western Development Regions. The lowest number of cases (54 cases) with mortality (CFR 29.6 percent) has been reported during the year 1981. The highest case fatality was observed in 1982 (CFR 46.3 percent). The overall mortality of JE varies from 8.5 percent (2004) to 46.3 percent (1982).

In Nepal, recommendations have been made on vector control/ insecticide spraying, awareness, vaccination, animal health sector coordination, water management and integrated farming and biological control for the prevention and control of JE. The government of Nepal had used DDT in very first intervention during 1994/95, followed by malathion during 1995/96, Lambdacyhalothrin and K-ornithrine etc. Currently, Lambdacyhalothrin is extensively being used in the visceral leishmaniasis, malaria and JE endemic districts of Nepal. However, insecticide spraying is not found effective in reducing JE cases.
The vaccination program was conducted in certain districts of Nepal during 1999 to 2001. Altogether, 121,000 children in Bardiya, 56,000 in Banke and 46,000 in Kailali were vaccinated against JE with SA-14-14-2 live attenuated BHK-vaccine in 1999. The population-based coverage was 83.5 percent in Bardiya, 41.3 percent in Banke and 21.9 percent in Kailali districts (The overall estimated coverage 45.5 percent). During 2001 and 2002, 2 millions doses of inactivated JE vaccine (total 4 doses) was administered among six months to 10 years agegroup population in Rupandehi, Dang, Banke, Bardiya, Kailali and Kanchanpur districts. Altogether, 481,421 children aged between 6months to 10 years were vaccinated during 2001/ 2002. It is revealed that in most instances the disease morbidity has been reduced except in Banke district during the year 2001. The incidence of the disease among non-vaccinated districts was found to be comparatively higher than the vaccinated districts. Vaccination has been found an effective intervention in reducing the JE morbidity and mortality. Therefore, it is recommended for regular JE vaccination in all endemic areas. Besides, the people visiting from non-endemic area to endemic areas, JE vaccination is highly suggestive.

\section{REFERENCES}

1. Ojha GP, Shrestha KD and Shrestha JM; Pokhrel RK, Upadhyaya P. Annual Report, 2001. Epidemiology and Disease Control Division, Department of Health Services, Ministry of Health, HMG/Nepal.

2. Joshi AB. Japanese Encephalitis in Nepal: A Five years Retrospective Review (1998-2003). Report submitted to the World Health Organization, SEARO, New Delhi. 2004.

\section{Key Words: Japanese encephalitis, Vaccination, Prevention.}

\author{
Address for correspondence : \\ Dr. Anand B. Joshi \\ Institute of Medicine, Tribhuvan University, Maharajgunj, Kathmandu, Nepal. \\ Email: research@healthnet.org.np
}

Received Date : $13^{\text {th }}$ March, 2005

Accepted Date : $17^{\text {th }}$ June, 2005 